NESA

\title{
Development of a PPT for the EO-1 Spacecraft
}

Scott W. Benson

Glenn Research Center, Cleveland, Ohio

Lynn A. Arrington

Dynacs Engineering Company, Inc., Brook Park, Ohio

W. Andrew Hoskins and Nicole J. Meckel

Primex Aerospace Company, Redmond, Washington

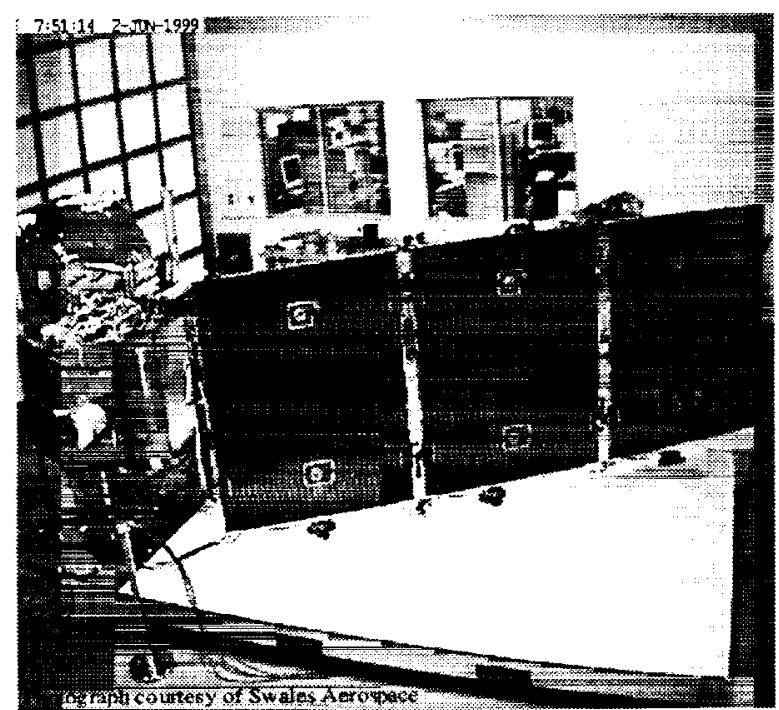


Since its founding, NASA has been dedicated to the advancement of aeronautics and space science. The NASA Scientific and Technical Information (STI) Program Office plays a key part in helping NASA maintain this important role.

The NASA STI Program Office is operated by Langley Research Center, the Lead Center for NASA's scientific and technical information. The NASA STI Program Office provides access to the NASA STI Database, the largest collection of aeronautical and space science STI in the world. The Program Office is also NASA's institutional mechanism for disseminating the results of its research and development activities. These results are published by NASA in the NASA STI Report Series, which includes the following report types:

- TECHNICAL PUBLICATION. Reports of completed research or a major significant phase of research that present the results of NASA programs and include extensive data or theoretical analysis. Includes compilations of significant scientific and technical data and information deemed to be of continuing reference value. NASA's counterpart of peerreviewed formal professional papers but has less stringent limitations on manuscript length and extent of graphic presentations.

- TECHNICAL MEMORANDUM. Scientific and technical findings that are preliminary or of specialized interest, e.g., quick release reports, working papers, and bibliographies that contain minimal annotation. Does not contain extensive analysis.

- CONTRACTOR REPORT. Scientific and technical findings by NASA-sponsored contractors and grantees.
- CONFERENCE PUBLICATION. Collected papers from scientific and technical conferences, symposia, seminars, or other meetings sponsored or cosponsored by NASA.

- SPECIAL PUBLICATION. Scientific, technical, or historical information from NASA programs, projects, and missions, often concerned with subjects having substantial public interest.

- TECHNICAL TRANSLATION. Englishlanguage translations of foreign scientific and technical material pertinent to NASA's mission.

Specialized services that complement the STI Program Office's diverse offerings include creating custom thesauri, building customized data bases, organizing and publishing research results ... even providing videos.

For more information about the NASA STI Program Office, see the following:

- Access the NASA STI Program Home Page at http://www.sti.nasa.gov

- E-mail your question via the Internet to help@sti.nasa.gov

- Fax your question to the NASA Access Help Desk at (301) 621-0134

- Telephone the NASA Access Help Desk at (301) 621-0390

- Write to:

NASA Access Help Desk

NASA Center for AeroSpace Information 7121 Standard Drive

Hanover, MD 21076 
NASA/TM-2000-210340

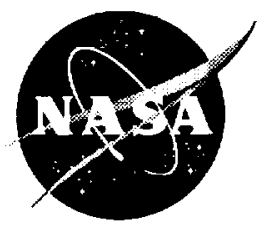

\title{
Development of a PPT for the EO-1 Spacecraft
}

\author{
Scott W. Benson \\ Glenn Research Center, Cleveland, Ohio \\ Lynn A. Arrington \\ Dynacs Engineering Company, Inc., Brook Park, Ohio \\ W. Andrew Hoskins and Nicole J. Meckel \\ Primex Aerospace Company, Redmond, Washington
}

Prepared for the

35th Joint Propulsion Conference and Exhibit cosponsored by AIAA, ASME, SAE, and ASEE

Los Angeles, California, June 20-24, 1999

National Aeronautics and

Space Administration

Glenn Research Center 


\section{Acknowledgments}

Many people at Primex Aerospace Company and NASA Glenn Research Center were involved in design, fabrication and test of the EO-1 PPT, the authors wish to acknowledge their contributions to this program.

The authors are particularly grateful to N. Speciale and C. Zakrzwski of the NASA GSFC for their continuing commitment to the PPT flight experiment.

Available from

NASA Center for Aerospace Information 7121 Standard Drive

Hanover, MD 21076

Price Code: A03
National Technical Information Service 5285 Port Royal Road Springfield, VA 22100 Price Code: A03 


\title{
DEVELOPMENT OF A PPT FOR THE EO-1 SPACECRAFT
}

\author{
Scott W. Benson \\ National Aeronautics and Space Administration \\ Glenn Research Center \\ Cleveland, Ohio 44135 \\ Lynn A. Arrington \\ Dynacs Engineering Company, Inc. \\ Brook Park, Ohio 44142 \\ W. Andrew Hoskins and Nicole J. Meckel \\ Primex Aerospace Company \\ Redmond, Washington 98023
}

\begin{abstract}
SUMMARY
A Pulsed Plasma Thruster (PPT) has been developed for use in a technology demonstration flight experiment on the Earth Observing I (EO-1) New Millennium Program mission. The thruster replaces the spacecraft pitch axis momentum wheel for control and momentum management during an experiment of a minimum three-day duration. The EO-1 PPT configuration is a combination of new technology and design heritage from similar systems flown in the 1970's and 1980's. Acceptance testing of the protoflight unit has validated readiness for flight, and integration with the spacecraft, including initial combined testing, has been completed. The thruster provides a range of capability from $90 \mu \mathrm{N}$-sec impulse bit at $650 \mathrm{sec}$ specific impulse for $12 \mathrm{~W}$ input power, through $860 \mu \mathrm{N}$-sec impulse bit at $1400 \mathrm{sec}$ specific impulse for $70 \mathrm{~W}$ input power. Development of this thruster reinitiates technology research and development and reestablishes an industry base for production of flight hardware. This paper reviews the EO-1 PPT development, including technology selection, design and fabrication, acceptance testing, and initial spacecraft integration and test.
\end{abstract}

\section{INTRODUCTION}

\section{Background}

Pulsed Plasma Thrusters (PPTs) offer unique benefits to a broad range of spacecraft. PPTs have been proposed for primary propulsion of small spacecraft for orbit raising and life extension of low earth missions (ref. 1). Several studies have shown the significant mass benefit of replacing wheels, torque rods and thrusters with an all PPT attitude control system (refs. 2 to 4). Fine impulse bit control enhances spacecraft attitude and positional control capabilities, providing enabling technology to optical interferometer spacecraft constellations envisioned for the future (ref. 5). The use of solid propellant allows extended fuelled storage and can eliminate the safety and leakage issues of on-board fluids and their associated systems. The simple spacecraft/PPT interface, limited to physical mounting hardware and electrical connections for power, commands and telemetry, provides flexibility to the spacecraft designer. Furthermore, thruster performance can be throttled over a wide range by varying pulse energy or pulse rate, providing additional implementation flexibility.

PPTs have already had a successful flight history, starting three decades ago and culminating in the extremely successfuI TIP/NOVA flights in which PPTs provided precision spacecraft positioning for several years each (ref. 6). The most recently launched PPT was built for NOVA in the early $1980^{\circ} \mathrm{s}$, after which research and development of PPTs subsided as the industry focussed on high power missions. However; the explosion of small satellite missions and the conceptualization of tightly controlled interferometry constellations has reignited interest in PPTs in the 1990s, led by the establishment of a PPT research and technology program at NASA Glenn Research Center (GRC) (ref. 7). In addition to internal and university grant research, a PPT technology development contract was awarded to Primex Aerospace Company (PAC) in December, 1994 to assess markets, to identify and evaluate 
technology options, to demonstrate critical technologies through breadboard testing, and to design and fabricate a flight-ready thruster. It was this contract that has produced the PPT for flight on the EO-1 spacecraft.

The purpose of the GRC/PAC project was to develop and deliver a PPT with significant improvements over the baseline PPT design, for the LES $8 / 9$ communications satellite (ref. 8), for demonstration aboard a flight experiment to be identified later. Market and technology assessments were conducted to identify likely PPT missions and technologies within the PPT with a high potential for improvement. Based on those assessments, modular breadboard hardware was developed and tested extensively at both PAC and GRC. In December 1996, GRC agreed to provide a protoflight PPT, produced by Primex, to the NASA Goddard Space Flight Center (GSFC) EO-1 project for a pitch axis attitude control experiment under the sponsorship of the NASA New Millennium and Cross-Enterprise Technology Development Programs. The PPT was delivered to Swales Aerospace in September 1998 for integration onto the spacecraft. In December 1999, EO-1 will launch with the first flight PPT in over 10 years.

\section{PPT Overview}

A pulsed plasma thruster, illustrated schematically in figure 1, is an electromagnetic device applicable to multiple spacecraft propulsion functions. The PPT energy storage unit is charged by spacecraft power, generally processed by PPT-dedicated electronics. The mechanical end of the thruster consists of an electrode pair in close proximity to a mass of solid inert propellant. The energy storage unit voltage is present across the thruster electrodes. The thruster pulse is initiated by activating an igniter; itself mounted in close proximity to the propellant bar. The igniter generates sufficient plasma to provide a path for discharge of the energy storage unit across the thruster electrodes. This main discharge ablates and ionizes propellant into a plasma slug. The plasma is accelerated out of the thruster through a Lorentz (J x B) force. Additional, non-ionized particles are accelerated by pressure forces. The PPT plume is quasi-neutral. As the propellant surface ablates, a spring forces the propellant bar forward, providing consistent electrode/propellant geometry. Reference 9 provides an extensive review of PPT configurations that have been tested and flown. PPTs have been operated with impulse bits in the range of $25 \mu \mathrm{N}$-sec to $2 \mathrm{mN}$-sec and specific impulse of 300 to $1000 \mathrm{sec}$, tailored to specific mission needs.

\section{EO-1 Mission}

The primary objective of the Earth Orbiting 1 mission is to demonstrate new technologies in Earth imaging instruments. The spacecraft, with an estimated mass of $529 \mathrm{~kg}$, will be launched into a sun-synchronous orbit following the Landsat 7 spacecraft, providing an opportunity to make direct comparisons in imaging data. In addition to imaging technologies, a number of complementary technologies were selected for demonstration on the mission, including the pulsed plasma thruster for attitude control.

A technology objective of the EO-1 mission is to demonstrate PPT operations for a minimum three-day duration experiment. The PPT will control the spacecraft pitch axis, temporarily replacing the corresponding momentum wheel in the primary attitude control system. The spacecraft will use the PPT to perform three primary functions. Throughout the experiment duration, the PPT will be used to counter environmental torque, generally firing at minimum energy levels. During spacecraft night, the spacecraft solar array must be rewound to prepare for sun tracking; the PPT will manage momentum during the rewind, firing at an intermediate energy level. During some orbits, the solar arrays will be parked to provide best conditions for science events, then accelerated back to resume sun tracking. In this most demanding mode, the PPT will fire at a high energy level to manage momentum. Based on a recent spacecraft attitude control system analysis, the EO-1 PPT carries sufficient fuel to support an operational life of up to one month.

\section{EO-1 PPT DEVELOPMENT}

The development of the EO-1 protoflight PPT is summarized in the overall program schedule shown in figure 2. 
The primary goals in the design of the flight unit PPT were as follows:

- Low overall system mass (less than $5 \mathrm{~kg}$ )

- Highly throttleable impulse bit

- High reliability

- Long life (to enable the flight qualification of the technology for future missions)

While the design of the EO-I PPT was strongly based on that of previously flight qualified design (refs. 8 and 10 ), several design improvements were required to achieve these design goals. These improvements were primarily in the design of the capacitor, electronics, and discharge initiation switching, as well as some of the materials selected for the flight structure. The key features of these design improvements are described below, followed by a review of the final EO-1 PPT design features and characteristics.

Capacitor Selection.-The energy storage unit is the heart of the PPT. From the start of the program, it was determined that the energy storage unit should be a capacitor due to the heritage of capacitive configurations. The LES $8 / 9$ and NOVA PPTs used a 17 and $30 \mu \mathrm{F}$ rolled film capacitors, respectively.

Several capacitor technologies were investigated, including tantalum, metallized film, stacked ceramics, and rolled film. Of those options considered, only stacked ceramics and rolled film capacitors were found likely to provide the high current capability critical for PPT operation. Several off-the-shelf models were procured and tested in comparison with an actual unit from a LES 8/9 PPT. The rolled film configuration was chosen due to its PPT heritage and energy density capability. While the stacked ceramic capacitors have intriguing advantages, such as the lack of fluid and a higher resistance to thermal effects, there were concerns about design integration, unknown pulse lifetime, lack of heritage in the PPT application.

Of the rolled film designs tested, a $30 \mu \mathrm{F}$ capacitor similar to that used on the NOVA PPT performed most impressively and was selected for further development. Working closely with Maxwell Laboratories, who had built both the NOVA flight units and the $30 \mu \mathrm{F}$ capacitor tested, significant design improvements were made over the state of the art, including:

- An improved dielectric combination for a better combination of energy density and life.

- Greatly improved core winding techniques developed by Maxwell, allowing for a more dense, consistent and reliable wind.

- Increased capacitance to $40 \mu \mathrm{F}$ to handle higher energy levels.

- Laser cut foils to further reduce failure-inducing flaws and improve life.

- A more robust ceramic bushing to allow tolerance of vibration loads and thermal expansion stresses.

- Improved internal winding termination to reduce inductance and improve thermal transfer

- Improved external electrode connections to minimize resistive and inductive losses.

The result was a flight capacitor that weighed $1.5 \mathrm{~kg}, 75$ percent of the baseline LES 8/9, while handling over twice the pulse energy over comparable lifetimes. The final capacitor design underwent life testing at NASA GRC, where more than 26 million pulses at $43 \mathrm{~J} /$ pulse were achieved before the test was completed with the capacitor still in good operating condition. Accelerated life tests at Maxwell indicated a pulse life at $43 \mathrm{~J} /$ pulse in excess of 40 million pulses.

Electronics Topology.-The major sections of the PPT electronic circuit are shown in a block diagram schematic in figure 3. The electronics are comprised of the charge converter, telemetry and command logic, EMI filter, and two discharge initiation circuits. To prevent radiative cross-coupling past the EMI filter, the housing was constructed with an integral EMI enclosure around the filter that is mechanically and electrically connected with the PWB via an EMI gasket.

Early in the program, PAC and LeRC decided to retain the LES 8/9 PPT electronics topology, specifically the basic flyback topology with $15 \mathrm{~V}$ command inputs, where practical, while focusing innovation on the implementation of that topology. For example, many discrete components in the LES $8 / 9$ were eliminated in favor of a single Pulse Width Modulator (PWM) chip to provide the control of the switching circuit. Transformers were significantly 
updated, with improved magnetics, capable of four times the power throughput in a smaller package. Higher reliability, higher density stacked ceramic capacitors were substituted for the tantalum capacitors of the LES 8/9.

Several individual components, such as the switching MOSFETs, were updated to more capable, more reliable modem parts.

Although the EO-1 mission only calls for an average power requirement of 10 to $20 \mathrm{~W}$, the electronics were designed to handle up to $120 \mathrm{~W}$, allowing flexibility to use the same design for a wide range of missions. Through use of integrated circuits, and the improved componentry, the entire power processing unit could be fit on a single printed wiring board (PWB). Despite doubling the power handling capability, the EO-1 electronics demonstrated a significant reduction in mass and volume relative to the LES $8 / 9$ baseline, as shown in figure 4.

Each discharge initiation (DI) circuit consists of a $1 \mu \mathrm{f}$ storage capacitor, a switch, and an isolation transformer for the high voltage pulse. The original design was strongly based on the original LES $8 / 9$ design. The DI capacitor is charged from a tap off of the main power transformer. For a fixed pulse energy application like LES $8 / 9$, this is compact and works well, but this also became a limitation later when the EO-1 mission requested a high degree of throttleability, because the spark plug voltage scales with the main pulse energy. This limitation became apparent after the life testing of the EO-1 flight unit, as expected igniter wear increased the required spark plug voltage, slightly increasing the minimum pulse energy and impulse bit capability of the unit. This limitation is an artifact of design decisions made before the EO-1 mission was identified and will be remedied by the next generation PPT electronics program being conducted by GRC.

There are three distinct grounds in the protoflight unit as shown in figure 5: signal (low voltage) ground, high voltage ground, and chassis. The EMI filter isolates the signal ground from the spacecraft power bus. Optocouplers and differential impedance isolate the signal ground from the spacecraft command and telemetry circuits, respectively. Further protection of the spacecraft is provided by large filter capacitors and a transorb connected to PPT chassis. Finally, the high voltage discharge ground (PPT cathode) is isolated from the low voltage ground by isolation transformers and a large coupling resistance between the grounds.

Discharge Initiation Circuit Switching.-The selection of a highly reliable, low mass, high energy switching device for the triggering of the discharge initiation circuits was a significant design challenge. During the technology assessment phase, several different types of devices were considered, including SCRs, power transistors, power MOSFETs, and IGBTS. The original LES $8 / 9$ design used SCRs. The power transistors were ruled out because of excessive base drive requirements. The MOSFETs were ruled out because of power and peak current limitations. The SCRs had the advantages of flight heritage and a higher resistance to radiation because of metal packaging. However; they are prone to latch up failures, have an electrically hot case in a configuration that is difficult to integrate on a low profile board, and have significantly higher mass than IGBTs. IGBTs were selected because they offered the following advantages over other devices:

- Higher peak current capacity, which maximizes spark plug peak voltage.

- Readily available in $1200 \mathrm{~V}$ configuration, which was almost twice the ratings of other devices.

- Smallest size and mass.

- Latch proof design, yielding higher system reliability.

During the performance testing of the EO-1 unit, it was determined that the IGBTs were sensitive to the PPT discharge, causing spurious discharges in the uncommanded DI circuit. This sensitivity also overstressed the IGBTs, causing premature failure. To still enable the use of IGBTs on the flight unit, the PPT electronics were modified to provide additional filtering of the DI circuit and a zener diode was installed at the gate of the IGBT for further protection. Additionally, the command structure of the PPT was modified to effectively disarm the nonfiring DI circuit. The PPT completed all acceptance testing after these modifications without any further spurious discharging or IGBT failures.

PPT Materials.- - To save mass, while providing high strength and high temperature capability, PAC incorporated the use of thermoplastics as much as possible in the PPT design. While the electronics/capacitor housing and mounting bracket was aluminum, much of the remaining structure was built from glass-reinforced PolyEther-Imide thermoplastic. The electrode supports, which require a significantly higher temperature capability, were made of PolyAmide-Imide thermoplastic. Previous flight qualified designs relied on ceramic electrode supports, which had raised concerns about fracture and production of free fragments under launch vibration conditions. 


\section{EO-1 PPT Design Features}

Following validation of technology improvements with a breadboard thruster, a design specifically for the EO-1 mission was developed. The EO-1 PPT configuration is consistent with the figure I schematic, but has two parallel and opposing thruster heads, each consisting of an electrode pair, igniter, propellant bar and support structure, to support the spacecraft pitch axis control function. Figure 6 illustrates the EO-1 protoflight unit, resting on a ground handling fixture. The energy storage unit, power processing electronics and mechanical thruster elements are integrated into a single unit. The energy storage unit, a $40 \mu \mathrm{F}$ capacitor, is potted into a single piece aluminum chassis, which also houses the electronics.

The striplines, fluorocarbon polymer fuel bars and electrodes are housed in an assembly of dielectric thermoplastic parts with aluminum brackets for stiffness. Two "horns" to contain the near field plume and local contamination are integral to the electrode housing. The electrode configuration has a $1.5 \mathrm{in}$. gap, with $1 \mathrm{in.}$ wide by $1.5 \mathrm{in}$. long parallel electrodes, which was one of the highest performing configurations in the breadboard tests. The igniters, a single spark plug for each thruster, are mounted flush with the inner surface of the cathodes, and are connected to the electronics via short high voltage harnesses. The close proximity of the electronics and igniters is intended to minimize radiated EMI from the spark plug cable.

The PPT is attached to the EO-I spacecraft with a conical aluminum mounting bracket designed to locate the thrust vectors in the pitch axis center of gravity plane. Two electrical harnesses provide power and command/ telemetry interfaces. The total mass of the EO-1 PPT is $\sim 4.9 \mathrm{~kg}$. The outside dimensions of the assembly are $28 \mathrm{~cm}$ wide from horn to horn, $35 \mathrm{~cm}$ long from the horn to the tip of the conical mounting bracket, and $19 \mathrm{~cm}$ high at the tips of the mounting bracket.

The EO-I PPT is operated via three commands from the spacecraft: a main capacitor charge command and a discharge initiation command for each of the two sides. The charge command charges the capacitor to the desired voltage as a function of the duration of the command pulse. The rising edge of a discharge command initiates the pulse with a spark on the desired side. The EO-1 PPT was set to pulse on a $1 \mathrm{~Hz}$ cycle to match the spacecraft attitude control command cycle, although higher charge rates can easily be accomplished with a change of resistor value.

The impulse bit is throttled by varying the duration of the charge command between 160 and $920 \mathrm{msec}$. The maximum is set by spacecraft cycle time constraints. The minimum is determined by the minimum voltage that the spark plug will produce a spark. Since the requirement for throttling was determined after the electronics topology had been fixed, the EO-1 design does not charge the discharge initiation circuit independently of the main capacitor. The result is that the spark plug voltage is reduced along with the main capacitor energy. Below the voltage corresponding to a $160 \mathrm{~ms}$ charge, determined in part by the condition of the spark plug, the plug will not reliably produce a spark.

The EO-1 PPT operates off $28 \pm 6 \mathrm{~V}$ power from the spacecraft. Seven telemetry datapoints are relayed back to the spacecraft. The voltage of the main capacitor and the two discharge circuit capacitors are monitored. Two thermistors are installed to monitor temperature at the main power transformer and the main capacitor case. Propellant quantity is monitored through a potentiometer formed by a conductive ink printed on the propellant bar housing and a wiper attached to each propellant bar.

Table I summarizes the primary characteristics of the EO-1 PPT. Since the configuration of the protoflight PPT and the assembly and test approach precluded measurement of mass loss per impulse bit and power electronics output voltage and current, some thruster characteristics are estimated based on relevant breadboard thruster data.

\section{Acceptance Test Program}

A protoflight unit acceptance test program was defined in accordance with the EO-1 program requirements per the EO-1 Verification Plan and Environmental Specification. The test program was planned to accomplish the following objectives:

(1) Verify PPT compatibility with specified vibration, thermal and EMI environments,

(2) Characterize PPT performance, EMI emissions and plume-induced contamination, verifying compliance with respective interface requirements, or supplying supplemental data,

(3) Demonstrate PPT functionality over the minimum 3-day flight experiment duration. 
The acceptance test program consisted of PPT functional testing, vibration tests, performance tests, a thermal vacuum test, a combined life/contamination test, EMI/EMC emissions and susceptibility tests. Additional testing was conducted in preparation for spacecraft integration and test (T\&T). The acceptance test program was split between Primex-conducted tests and NASA Glenn Research Center-conducted tests.

Functional Testing.-Validation of the functionality of the PPT took two different forms: bench top testing, where the unit was discharged into an external resistive load on the laboratory benchtop, and vacuum functional testing, where the PPT was actually fired in the vacuum chamber. Each test was performed a number of times on the unit through out the protoqual testing to verify that the performance of the unit had not been compromised during the protoqual efforts. Each test successfully confirmed functionality of the PPT.

The benchtop test verified the basic electrical capabilities of the main charge converter (used to charge the large capacitor) and the discharge initiation circuits. Specific parameters that were monitored included the following: inrush current, input and output currents and voltages during operation, telemetry signals, and sparkplug discharge capability. An interelectrode test adapter was developed for these tests to link the PPT electrodes directly to the external resistive load. This adapter insulated the electrodes from each other while connecting each of the electrodes to the external resistive load. A small tap enabled electrode voltage to be measured directly with a high voltage probe.

Vacuum functional tests were performed in Vacuum Facility 6 at PAC. The PPT was fired at 5 and $56 \mathrm{~J}$, thus verifying the impulse range of the thruster. Additional parameters that were verified included the following: input power range, telemetry signals, fuel bar potentiometer signals, and thermistor readings (before and after 500 pulse tests). In each case the performance of the PPT was verified.

Vibration Testing.-The PPT was subjected to random vibration at a level of $14.1 \mathrm{~g}$ for $1 \mathrm{~min}$ in each axis. These levels reflect the launch loads for the Delta launch vehicle for the EO-1 spacecraft. This random vibration test was successfully completed with no significant damage to the PPT. The PPT was mounted as it would be on the spacecraft: on the conical mounting structure, with thermoplastic washers (which act as thermal isolators on the spacecraft) between the conical mount and the vibration fixture. The test sequence included a sine sweep to determine fundamental modes (in each axis), followed by the random vibration, and completed with a 'post-test' sine sweep to verify that the modes had not changed as a result of the test (which would be symptomatic of structural damage). The first mode occurred at $185 \mathrm{~Hz}$, which exceeded spacecraft minimum requirements of $100 \mathrm{~Hz}$ by a significant margin. The post test sine sweep did not reveal any shifts in the fundamental modes.

Thermal/Vacuum Test.- Thermal testing was conducted in Vacuum Facility 13 at NASA GRC. Four cycles with thruster firings at operating temperature extremes and soaks at survival temperature extremes were required. The predicted operating and survival temperatures were based on thermal analyses and test temperatures employed were $10^{\circ} \mathrm{C}$ beyond the predicted levels. Figure 7 illustrates the test sequence and temperature conditions. Per the analyses, the hottest temperature the PPT will be subjected to is during PPT operations, so the operation and survival temperatures were combined, with the $2 \mathrm{hr}$ soak preceding thruster operations. The PPT was also operated for $10 \mathrm{~min}$ during one transition from cold-to-hot conditions. Cold survival temperatures in the range of -27.3 to $-28.9^{\circ} \mathrm{C}$, over the four cycles, were the best achieved due to test equipment, setup and environment effects.

The PPT operated successfully over the four temperature cycles. There was no variation in performance characteristics between pre- and post-test ambient operations, and all operations at hot and cold extremes were essentially identical. However; during the first cold operating test, it was discovered that the PPT capacitor was charging at a different rate than seen during ambient temperature tests. The main capacitor and discharge circuit capacitors charged more quickly, resulting in a higher-than-expected voltage level for a given charge duration, and an associated increase in current draw. Per the circuit design, the PPT goes into voltage regulation to preclude overcharging the capacitor. At the hot operating temperature, the PPT charges more slowly, resulting in lower-than-expected charge voltage and associated current draw. This temperature-dependent performance was identical over the four temperature cycles, and was thus deemed a characteristic of the design. The spacecraft control system algorithms encompass the variability in impulse bit caused by this effect. Throttling based on a charge voltage feedback loop, as opposed to open loop throttling through control of charge duration, can be used to eliminate the impulse bit variability due to unit temperature.

Contamination/Life Test.-A combined test was conducted in the NASA GRC Vacuum Facility 13 to demonstrate life capability of the prototype thruster and to characterize contamination on spacecraft surfaces. A mockup of representative spacecraft surfaces was used to place selected spacecraft surface samples in locations approximating the spacecraft geometry, shown in figure 8 . The contamination test was conducted during the side 1 life test, during which the PPT installation on the test fixture represented the actual location on the spacecraft. 
Based on NASA GSFC mission analysis, a life test duration of 100000 pulses per side, at a charge duration of $320 \mathrm{msec}(18.7 \mathrm{~J})$, was selected. The analysis reveals that the majority of the PPT operations occur with charge duration of about $320 \mathrm{msec}$ and below. This level also reduced potential concems with overheating the PPT by firing continuously at high energies in a ground test environment.

The PPT was fired continuously, once per second, during each test run. Each half of the life test was conducted over multiple days, with the PPT shut down overnight. The PPT operated successfully through the entire test sequence of over 200000 pulses.

The contamination test was performed to determine the effect of the PPT plume on three different types of spacecraft surfaces, the X-band antenna, a radiator surface of silver-teflon tape, and the MLI which covers the spacecraft panels. Surface samples were provided by GSFC. The samples were installed on the spacecraft mock-up for the side 1 life test. Sample locations are noted in figure 8. Control samples were not exposed to PPT operations or vacuum. As the PPT had to be rotated $180^{\circ}$ for the side 2 life test, the orientation no longer represented the PPT/ spacecraft geometry, and the samples were removed from the test fixture for evaluation.

The X-band antenna specimens were evaluated pre- and post-test through exposure to 8 to $12 \mathrm{GHz}$ signals at the NASA GRC Compact Range Facility. Both pre- and post-test results demonstrated minimal differences between exposed and control samples. Reflectance measurements of the radiator and MLI samples were made through spectrophotometry over a wavelength range of 350 to $1200 \mathrm{~nm}$. Radiator samples exhibited no significant change in characteristics; total reflectances over a range of 350 to $900 \mathrm{~nm}$ varied less than 0.5 percent between the contaminated and control specimens. There was no change in emittance for the radiator samples. The MLI sample suffered a 6 percent reduction in total reflectance, as compared to the control sample; however, this sample was placed in a worst-case location under the thruster, as seen in figure 6 . The MLI specimen was not visibly damaged.

The contamination test samples were returned to GSFC for further evaluation. While there were no specific pass/fail criteria, contamination test data indicate that PPT plume-induced contamination is not an issue. Additional contamination testing has been performed at NASA GRC (ref. 11) using the breadboard PPT provided by Primex Aerospace and quartz samples distributed around the PPT plume.

EMI.--Electromagnetic interference/compatibility testing was conducted at NASA GRC to characterize protoflight PPT emissions. The emissions test approach consisted of a battery of tests designed to characterize the conducted and radiated EMI emissions of the PPT unit in a manner that would allow comparison of results to established standards. While such tests are common for spacecraft components, the PPT presented two unusual complications in administering these measurements. First, the PPT must be operated only in a vacuum environment. Secondly, it is a pulsed device with a very low duty cycle electric discharge that dominates its EMI emissions. These factors prevented conventional EMI test facility setups and methods from being used. A portable glass bell jar vacuum facility (VF 55) was modified to support testing. Manual frequency tuning and time domain observation of emissions supplemented, or replaced when necessary, conventional automated frequency sweeps. Tests were conducted as closely as practical to the guidelines designated in MIL-STD-462. MIL-STD-461C methods and limits, tailored to EO-1, were applicable. The conducted emissions CE01, CE03 and CE07 tests, and radiated emissions RE01 and RE02 tests were performed. In general, the PPT was pulsed at full energy during the emissions tests to generate worst case environments.

Conducted emissions over the frequency range of $30 \mathrm{~Hz}$ to $15 \mathrm{kHz}$ (CE01) were found to be well within the limit specification. Conducted emissions in the $15 \mathrm{kHz}$ to $50 \mathrm{MHz}$ frequency range (CE03) exhibited several conditions in which the emissions exceeded the specification limit. In considering these emissions, it is important to separate the emissions associated with the steady state charge cycle of the thruster from the transient events associated with the spark plug firing and the main discharge, which appear as the comb-like spikes in the plots. The latter are more appropriately assessed under the CE07 limits. As seen in figure 9, the PPT exceeds the specification limits at $57 \mathrm{~Hz}$ and over the range $400 \mathrm{kHz}$ to $4 \mathrm{MHz}$, by as much as $\sim 12 \mathrm{~dB}$. The base of this curve, ignoring the spikes . associated with the discharge events, represents the emissions during the charge cycle of the PPT operations, or up to $920 \mathrm{msec}$ out of each second. The plot is representative of other test conditions, including sensing of the $+28 \mathrm{~V}$ lead and firing at other throttled energy levels. Subsequent investigation through time domain measurements substantiated separation of the charge electronics, spark plug firing and main discharge contributions to the emissions environments.

The CE07 test involves the measurement of voltage spikes induced on the primary power lines by switching or cycling of the unit under test. For the EO-1 PPT CE07 testing, a special RLC network and cable combination was used to simulate the EO-1 power bus. Worst case voltage spike magnitudes of 3 to $5 \mathrm{~V}$ peak-to-peak were well 
within the EO-1 specification of +50 to -150 percent limit bands. By eliminating radiated emissions effects on the test set-up, measured conducted voltage spikes were further reduced.

The spark plug firing and/or main discharge events, occurring once per second with $\mu$ sec duration dominate radiated emissions. The emissions were very broadband in nature, detected to $\mathrm{GHz}$ frequencies, and exhibited a large shot-to-shot scatter. The emissions appear to be isotropic. Radiated emissions from the charge electronics could not be detected due to threshold settings necessary to characterize the discharge events. The $\mu$ sec duration emission events exceeded the RE02 broadband specifications by 50 to $75 \mathrm{~dB}$ at frequencies below $1 \mathrm{MHz}$ as seen in figure 10. This high level of low frequency noise is not uncommon for other plasma type thrusters or electric discharges. The emissions remained substantial to several $\mathrm{GHz}$, possibly posing a general concern for spacecraft communication receiver performance. However; these short duration transient effects can be handled operationally or through data correction algorithms. Radiated magnetic field emissions were similarly dominated by the ignition/ discharge events. Charge cycle emissions were verified to be within RE01 limits. Broadband emissions from the transient discharge events are not directly comparable to the RE01 specification, however levels exceeded the standard RE01 limit at frequencies above $300 \mathrm{~Hz}$.

Due to the emissions characteristics of the protoflight PPT, a separate test was incorporated into the spacecraft integration and test program to accept compatibility of the spacecraft and PPT. This successful test is described in the I\&T section below.

EMC.-Susceptibility testing was conducted at NASA GRC, using the vacuum bell jar described above and the NASA GRC EMI test facility. The PPT operated successfully over the entire range of CS01, CS02, CS06 and RS03 tests and conditions. There was no change to PPT functionality in post-test operations. Voltage noise was present in the PPT telemetry channels during some of the susceptibility testing. PPT data is not an input into autonomous spacecraft operations and is only downlinked for data analysis; therefore, possible telemetry degradation has no effect on mission objectives.

Performance Testing.-Performance testing was conducted at both Primex and NASA GRC. The Primex Vacuum Facility 6 and associated thrust stand were used for initial characterization of PPT functionality. A full range of performance measurements were taken at GRC in the Vacuum Facility 3, using the GRC PPT thrust stand. References 12 and 13 provide a full description of performance testing on both the EO-1 protoflight and breadboard PPTs, including discussion of results. This paper provides a summary of key protoflight data only.

Primary axis impulse bit and thrust were measured, for both PPT sides, at five energy levels. While thrust can be calculated from impulse bit using the pulse frequency, both characteristics were determined experimentally. The results are provided in table II.

A significant result of the primary axis testing was measurement of a difference in performance between the two thruster heads. Additionally, shot-to-shot variation was measured. EO-1 program and schedule considerations precluded investigation into the nature of these features on the flight unit.

During performance testing of the breadboard PPT, it was noted that there was a measurable off-axis component of the PPT pulse. Therefore, each side of the EO-1 PPT was characterized for off-axis thrust by measuring performance along two axes orthogonal to the primary axis. The tests showed a thrust component in the direction of the anode, as the expelled plasma was deflected towards the cathode electrode on each PPT side. The deflection angle between the thrust vector and the primary axis is within $5.5^{\circ}$ for all operating conditions.

After completion of the life test of the acceptance test program, primary axis performance was again measured to determine whether the PPT impulse bit and thrust had changed. There were modest changes in the performance parameters noted; however, absolute changes in performance characteristics could not be discriminated from test set-up effects. During this test, it was determined that the PPT no longer fired reliably at the lowest desired capacitor charge duration of $120 \mathrm{msec}$, or energy of $\sim 6.4 \mathrm{~J}$. The change in minimum firing range is attributed to spark plug wear over the 100000 pulse life test. Spark plug breakdown characteristics have been shown to vary between sparkplugs and over time. These typical changes have been identified as causes for the change in PPT performance (ref. 5). The minimum charge duration for operational use was therefore changed to $160 \mathrm{msec}$, or energy of $8.5 \mathrm{~J}$.

In addressing the EO-1 performance requirements on the PPT, a number of factors had to be considered. The EO-I program need was to characterize the actual impulse bit against the commanded charge duration. An impulse bit range, vs. charge duration, was developed that accommodated three sources of variation:

- shot-to-shot variation, due to random changes in the discharge characteristics,

- apparent characteristic difference in performance between side 1 and side 2,

- capacitor charging differences due to PPT temperature, as discussed in the Thermal/Vacuum Section above. 
The final EO-1/PPT Interface Control Document impulse bit range, as determined by test and analysis, is presented in the figure 11 .

A number of methods exist for decreasing the range of impulse bit variability, for both the EO-1 PPT and for future PPT units based on similar technology. In future PPTs, circuit or component changes can be implemented to reduce thermal sensitivity or alter the throttling approach, therefore negating thermal effects. Changes to the spark plug initiation circuit, and the spark plug itself, could also improve shot-to-shot variability and low throttle level reliability. To narrow the shot-to-shot uncertainty for EO-1, the operating temperature range could be reduced analytically by modeling expected PPT operations; and the impulse bit variation could be reduced statistically using relevant breadboard PPT performance data. Due to the EO-1 program constraints, and the general flight experiment objectives, the EO-1 PPT performance was accepted without further analysis or test to yield such improvements. Research continues at GRC, with both laboratory activities and an upcoming electronics research contract.

\section{Spacecraft Integration and Test}

Integration of the PPT to the spacecraft occurred in two phases. During December 1998, initial electrical interface testing was conducted to demonstrate spacecraft electromagnetic compatibility with PPT operations. Because of the conducted and radiated emissions measured from the protoflight PPT, there was significant concern that PPT pulses may upset the spacecraft processor or associated electronics. After safe-to-mate checks, the PPT was electrically mated to the spacecraft and operated in two modes. During the first sequence, the PPT, in ambient conditions, was discharged into a resistive load box to demonstrate spacecraft/PPT functionality. Assorted test equipment was required to capture either igniter spark as a signal, transform the signal into a command to the load box, and effect the discharge into the load box. The spacecraft/PPT electrical interface checked out per specification. The PPT was then installed into a vacuum bell jar provided by NASA GSFC and remated to the spacecraft electrical interface. The PPT was fired in vacuum while the spacecraft systems were observed. The PPT and the spacecraft operated nominally over the range of test conditions. Demonstration of flight-like operations substantiated that the protoflight PPT EMI emissions do not represent a threat to normal spacecraft operations.

The second phase of integration occurred when the PPT was mechanically mated to the spacecraft in April 1999. The electrical interface was reverified using the test equipment for ambient PPT operations. All aspects of the integration went as planned.

The PPT will be operated, using the ambient discharge support equipment, during spacecraft Comprehensive Performance Tests (CPT). After spacecraft major integration and test milestones, the spacecraft CPT will be conducted to verify overall functionality. The PPT will be operated in an open loop manner, with a specific sequence of commands, and a closed loop manner, in which the spacecraft ACS will operate the PPT in response to simulated disturbances.

The final PPT I\&T milestone will be a vacuum firing during spacecraft thermal/vacuum testing. Kapton enclosures have been fabricated to capture the extremely small quantity of plume products generated during the firing. In a previous PPT flight program, PPT operations during spacecraft level vacuum tests have induced PPT failure (ref. 14); the cause was identified and well understood. Features of the EO-1 PPT design preclude reoccurrence of this problem; however, test set-up will be thoroughly assessed with the spacecraft team.

Launch of the EO-1 spacecraft is currently scheduled for December 1999. Two windows exist for conducting the PPT flight experiment: during early orbit operations and/or after the first season of imaging experiments. Completion of the three-day experiment may lead to continued operations; the PPT has sufficient propellant to support up to one month of nominal operations.

\section{FUTURE PPT APPLICATIONS}

PPTs continue to enjoy growing interest for a wide range of on board propulsion applications. PPTs show positive mass benefits when replacing wheels, torque rods and chemical thrusters for attitude control on spacecraft of all sizes (refs. 2 to 4). The principle hurdles to widespread use are flight experience and technology maturity, both of which will be addressed with the EO-1 flight and an upcoming NASA GRC PPT electronics program. However; the EO-1 unit represents an excellent baseline for a primary attitude control system design and could be implemented with minor modifications to address the EO-1 lessons learned, add more propellant, or reorient the thrust vectors as necessary. 
Other applications of continued and newly developed interest are orbit raising, constellation maintenance, and micro-satellite propulsion. Many small, low Earth orbit, spacecraft would benefit from PPTs as primary propulsion, to either extend mission life or allow launch on a smaller vehicle. The development directions for this application are increased power handling and thrust to power ratio. PPTs are a strong contender as a technology demonstration of constellation maintenance, which includes both attitude and translational position control, on the Space Technology 3 (ST-3, formerly DS-3) mission (ref. 5). This demonstration would lead into an enabling role on later generation Origins missions, such as Terrestrial Planet Finder. The longer the mission, the more favorably PPTs trade against cold gas from a mass perspective. Finally, for very small satellites, in the $10 \mathrm{~kg}$ total mass region, miniaturized PPTs become one of the few viable options for on-board propulsion. The small impulse bit is much more easily scaleable for spacecraft of this size than systems with tanks and valves.

\section{CONCLUSION}

A new pulsed plasma thruster will fly on the Earth Orbiting 1 mission, demonstrating application to small spacecraft attitude control. While retaining design heritage from previous PPTs, improvements in electronics technologies and capacitor design, and advanced packaging and use of lightweight materials has resulted in a smaller, lighter and more versatile thruster. PPT throttling will be demonstrated for the first time, providing capability to respond to a variety of spacecraft control requirements. The protoflight PPT successfully passed all acceptance testing and has been integrated to the spacecraft. PPT evaluation will continue through the spacecraft level test program. A three-day flight experiment will validate the design, providing a departure point for implementation on a variety of potential future missions.

\section{REFERENCES}

1. LeDuc, J.R., Bromaghim, D.R., Peterson, T.T., Pencil, E.J., Arrington, L.A., Hoskins, W.A., Meckel, N.J., and Cassady, R.J., "Mission Planning, Hardware Development, and Ground Testing for the Pulsed Plasma Thruster (PPT) Flight Demonstration on MightySat II.1," AIAA-97-2779, July 1997.

2. Cassady, R.J., Myers, R.M., Osborne, R.D., "Pulsed Plasma Thrusters for Spacecraft Attitude Control," Proceedings of the 1996 JANNAF Propulsion Meeting, Dec. 1996.

3. Meckel, N.J., Cassady, R.J., Osborne, R.D. Hoskins, W.A., and Myers, R.M., "Investigation of Pulsed Plasma Thrusters for Spacecraft Attitude Control," IEPC-97-128, Aug. 1997.

4. Cassady, R.J., Morris, J.P., Vaughan, C.E., Willey, M.J., "New Attitude Control Strategies Using Pulsed Plasma Thruster Systems," AAS 98-065, February, 1998

5. Cassady, R.J., Willey, M.J., Meckel, N.J., and Blandino, J.J., "Pulsed Plasma Thruster for the New Millennium Space Interferometer Experiment DS-3," AIAA-98-3326, July 1998.

6. Ebert, W.L., Kowal, S.J., and Sloan, R.F., "Operational NOVA Spacecraft Teflon Pulsed Plasma Thruster System," AIAA-89-2497, July 1989.

7. Curran, F.M., Peterson, T.T., and Pencil, E.J., "Pulsed Plasma Thruster Technology Directions," AIAA-97-2926, July 1997.

8. Vondra, R.J., and Thomassen, K L., "Flight Qualified Pulsed Electric Thruster for Satellite Control," Journal of Spacecraft and Rockets, Vol. 11, No. 9, 1974, pp. 613-617.

9. Burton, R.L., and Turchi, P.J., "Pulsed Plasma Thruster," Journal of Spacecraft and Rockets, Vol. 14, No. 5, 1998, pp. 716-735.

10. Brill, Y., Eisner, A., and Osborn, L., "The Flight Application of a Pulsed Plasma Microthruster," The NOVA Satellite," AIAA-82-1956, Nov. 1982.

11. Myers, R.M., Arrington, L.A., Pencil, E.J., Carter, J., Heminger, J., and Gatsonis, N., "Pulsed Plasma Thruster Contamination," AIAA-96-2729, July 1996.

12. Arrington, L.A., and Haag, T.W., "Multi-Axis Thrust Measurements of the EO-1 Pulsed Plasma Thruster," AIAA-99-2290, June 1999.

13. Arrington, L.A., Haag, T.W., Pencil, E.J., and Meckel, N.J., "A Performance Comparison of Pulsed Plasma Thruster Electrode Configurations," IEPC-97-127, Aug. 1997.

14. Vondra, R.J., "The MIT Lincoln Laboratory Pulsed Plasma Thruster," AIAA-76-998, Nov. 1976. 
TABLE I.-EO-1 PROTOFLIGHT PPT CHARACTERISTICS

\begin{tabular}{|l|l|}
\hline Type & Rectangular, parallel plate, breech fed propellent \\
\hline Thrust axis & Two parallel and opposing \\
\hline Impulse bit & 90 to $860 \mathrm{mN}-\mathrm{sec}^{\mathrm{a}}$ continuously throttleable \\
\hline Specific impulse & $650 \mathrm{to} 1400 \mathrm{sec}^{\mathrm{a}}$ \\
\hline Total impulse & $450 \mathrm{~N}$-sec \\
\hline Pulse frequency & Single pulse or $1 \mathrm{~Hz}$ \\
\hline Stored energy & 8.5 to $56 \mathrm{~J}$, throttleable \\
\hline Input power & $70 \mathrm{~W}^{\mathrm{a}}$ at $28 \mathrm{~V}$, maximum energy, 1 pps \\
\hline Overall efficiency & 8 percent at maximum energy \\
\hline PPU efficiency & 81 percent $\mathrm{t}^{\mathrm{a}}$ \\
\hline Capacitor & $40.1 \mu \mathrm{F}, 2 \mathrm{kV}$ \\
\hline Thruster mass & $4.95 \mathrm{~kg}$ \\
\hline Fuel mass & $0.07 \mathrm{~kg}$ per side \\
\hline Fuel & Rectangular cross-section fluorocarbon polymer bars \\
\hline
\end{tabular}

"Estimated based on breadboard thruster data.

'Estimated based on expected EO-1 operations.

TABLE II.-NOMINAL PERFORMANCE OVER THE EO-I PPT

\begin{tabular}{|c|c|c|c|c|c|}
\hline \multirow{2}{*}{$\begin{array}{c}\text { Charge time, } \\
\text { ms }\end{array}$} & \multirow{2}{*}{$\begin{array}{c}\text { Energy, } \\
\quad \mathrm{J} \\
\text { estimated }\end{array}$} & \multicolumn{2}{|c|}{ Side I } & \multicolumn{2}{|c|}{ Side 2} \\
\hline & & $\begin{array}{c}\text { Thrust, } \\
\mu \mathrm{N}\end{array}$ & $\begin{array}{c}\text { Impulse bit, } \\
\mu \mathrm{N}-\mathrm{sec}\end{array}$ & $\begin{array}{l}\text { Thrust, } \\
\mu \mathrm{N}\end{array}$ & $\begin{array}{c}\text { Impulse bit, } \\
\mu \mathrm{N}-\mathrm{sec}\end{array}$ \\
\hline 920 & 55.8 & 789 & 812 & 854 & 856 \\
\hline 720 & 43.2 & 602 & 602 & 652 & 663 \\
\hline 520 & 30.1 & 408 & 408 & 465 & 469 \\
\hline 320 & 18.7 & 225 & 226 & 268 & 266 \\
\hline 120 & 6.4 & 59 & 59 & 65 & 65 \\
\hline
\end{tabular}

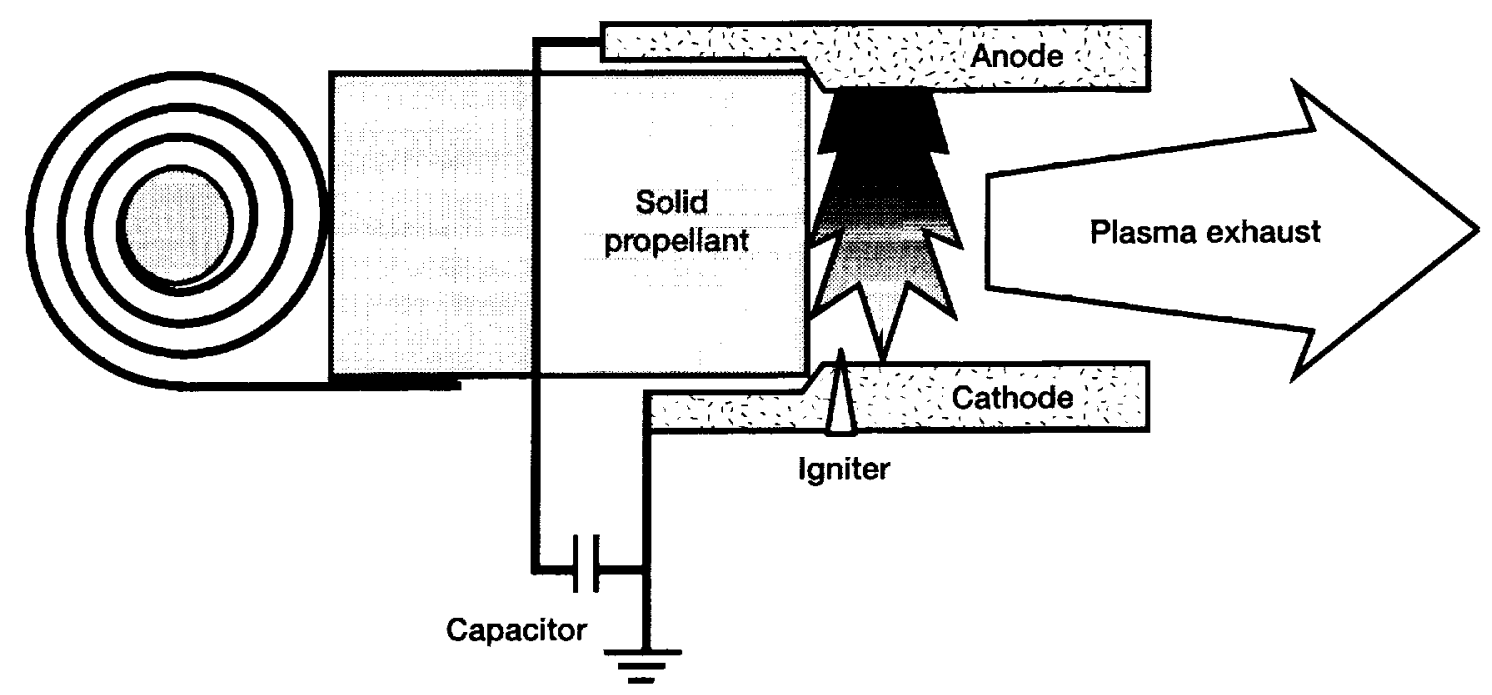

Figure 1.-Pulsed plasma thruster schematic diagram. 


\begin{tabular}{|c|c|c|c|c|c|c|c|c|}
\hline ID & Task Name & \begin{tabular}{|c|c|} 
& 1994 \\
094 & 19210310
\end{tabular} & 1995 & 1998 & 1897 & \begin{tabular}{l|l}
1998 \\
\end{tabular} & & \begin{tabular}{|l|l}
1999 & \\
\end{tabular} \\
\hline & & $|04| Q_{1}\left|Q_{2}\right| Q 3 \mid Q$ & $4|01102| 03 \mid 04$ & \begin{tabular}{|l|l|l|l|l|l|l|l|l|l|l|} 
& 02 & 03 & 04 \\
\end{tabular} & 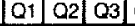 & \begin{tabular}{l|l|l|l|l|l|} 
& 01 & 02 & 03 \\
\end{tabular} & 04 & \begin{tabular}{|l|l|l|l|l|l|l|}
01 & 02 & 03 & 04 & 01 \\
\end{tabular} \\
\hline 1 & GRC/PAC Program Kickoff & & & & & & & \\
\hline 2 & Development Program & & & & & & & \\
\hline 3 & Market Survey and Tech. Assess. & & 氺 & & & & & \\
\hline 4 & Breadboard PPT Design/Fabrication & & ए & - & & & & \\
\hline 5 & Breadboard PPT Testing at PAC & & & 逄 & & & & \\
\hline 6 & Breadboard PPT Dellvery to GRC & & & 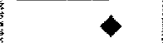 & & & & \\
\hline 7 & Breadboard Testing at GRC & & & & & & & \\
\hline 8 & EO-1 Mission Opportunity Identified & & & 4 & & & & $\vdots$ \\
\hline 9 & EO-1 Protoflight PPT Development & & & & & & & $\vdots$ \\
\hline 10 & Flight System Design & & & & $=0$ & & & $\vdots$ \\
\hline 11 & Design Review & & & & $\bullet$ & & & \\
\hline$\overline{12}$ & EO-1 PPT Fabrication & & & & & 然 & & \\
\hline 13 & Acceptance Testing at PAC & & & & & 姃 & & \\
\hline 14 & EO-1 PPT Delivery to GRC & & & & & $\bullet$ & & 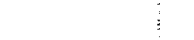 \\
\hline 15 & Acceptance Testing at GRC & & & & & 㴗 & & \\
\hline$\overline{16}$ & EO-1 PPT Dellvery to GSFC/Swales & & & & & $\bullet$ & & \\
\hline 17 & EO-1 18T and Mission & & & & & & & 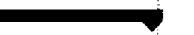 \\
\hline 18 & Spacecraft Integration and Test & & & & & & & 閣 \\
\hline 19 & EO-1 Launch & & & & & & & $\bullet$ \\
\hline 20 & & & & & & & & \\
\hline 21 & & & & & & & & \\
\hline 22 & & & & & & & & \\
\hline 23 & & & & & & & & \\
\hline 24 & & & & & & & & \\
\hline
\end{tabular}

Figure 2.-EO-1 PPT Development program summary.

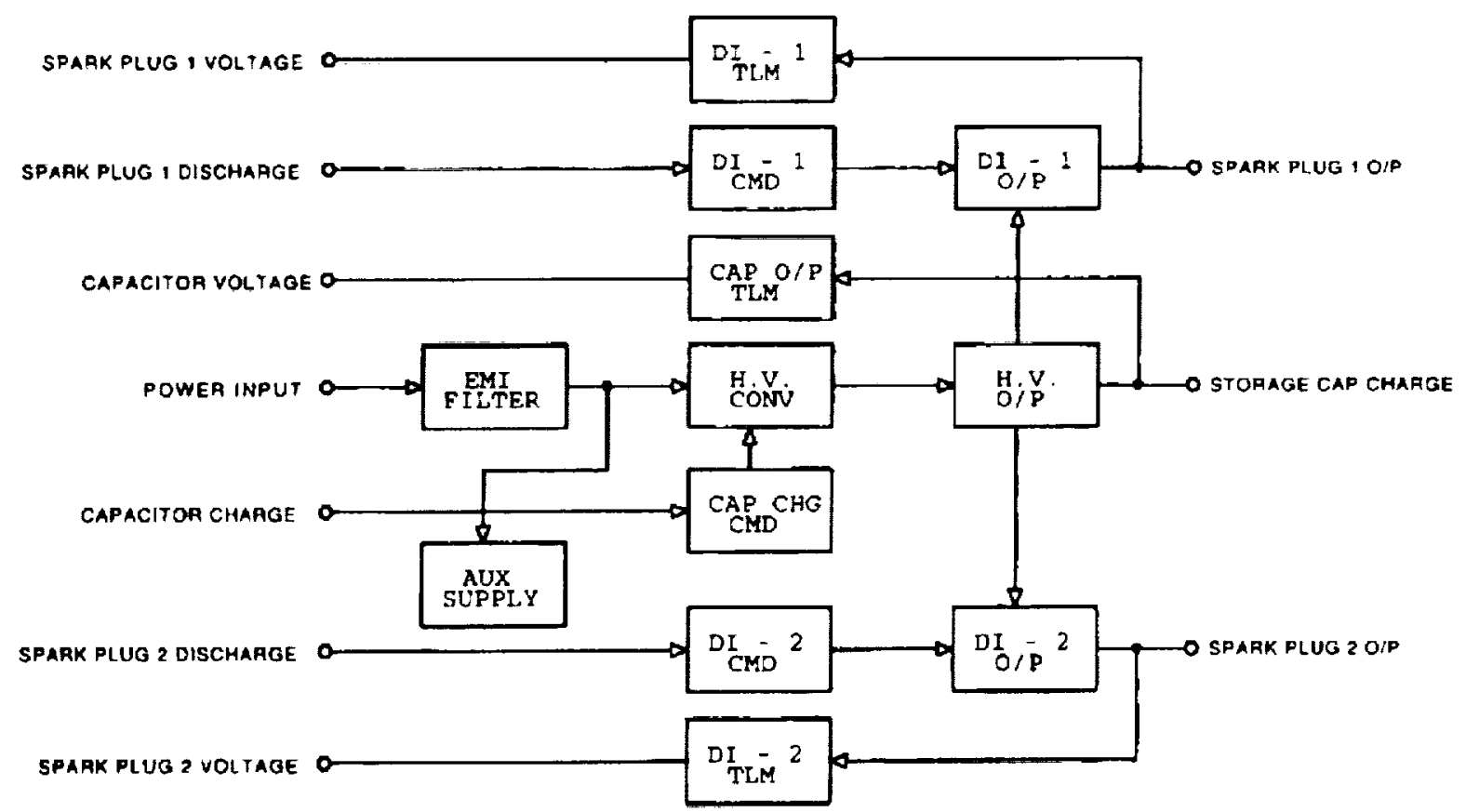

Figure 3.-EO-1 PPT electronics schematic block diagram. 


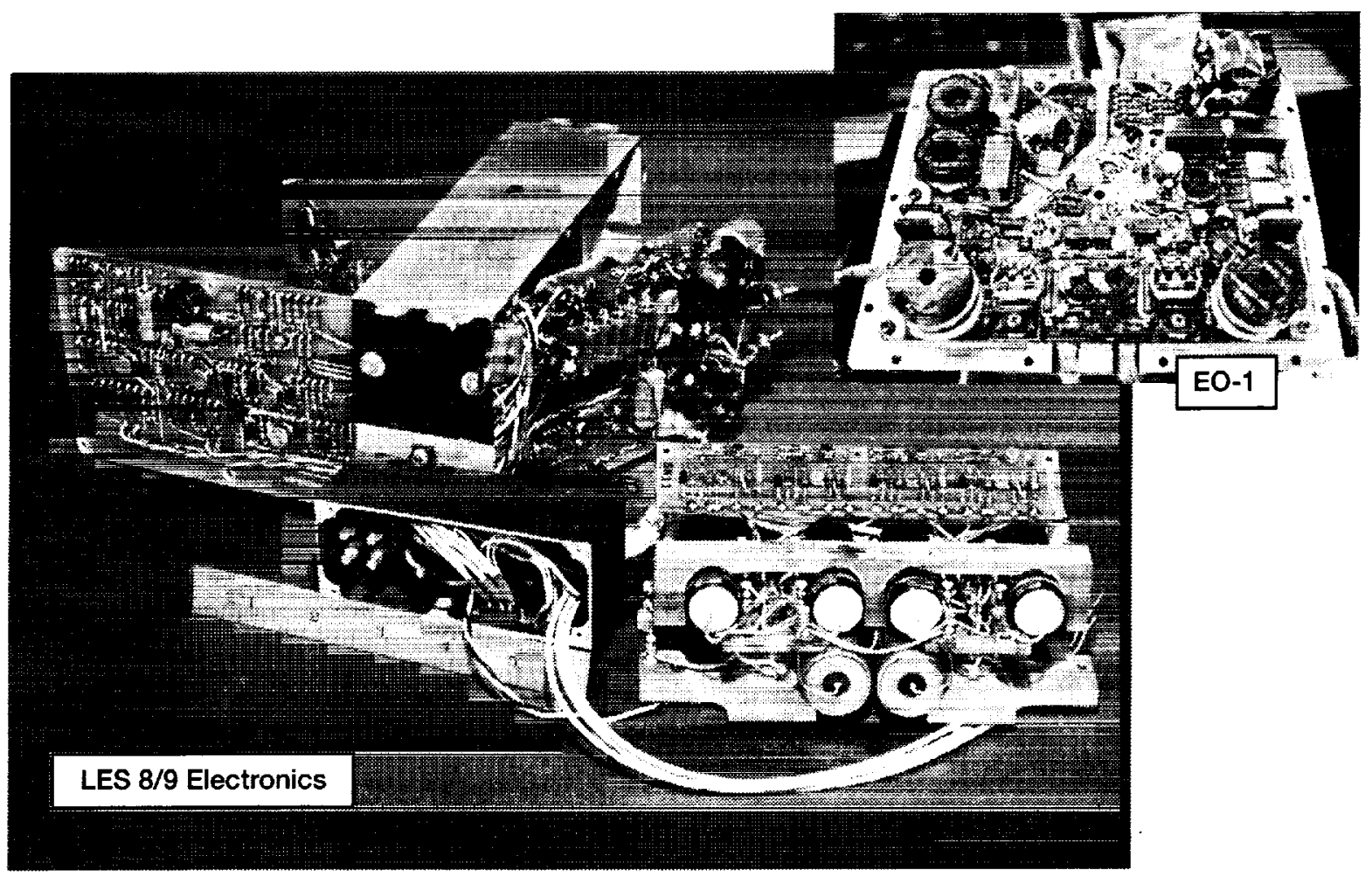

Figure 4.-Comparison of EO-1 and LES 8/9 electronics (to scale).

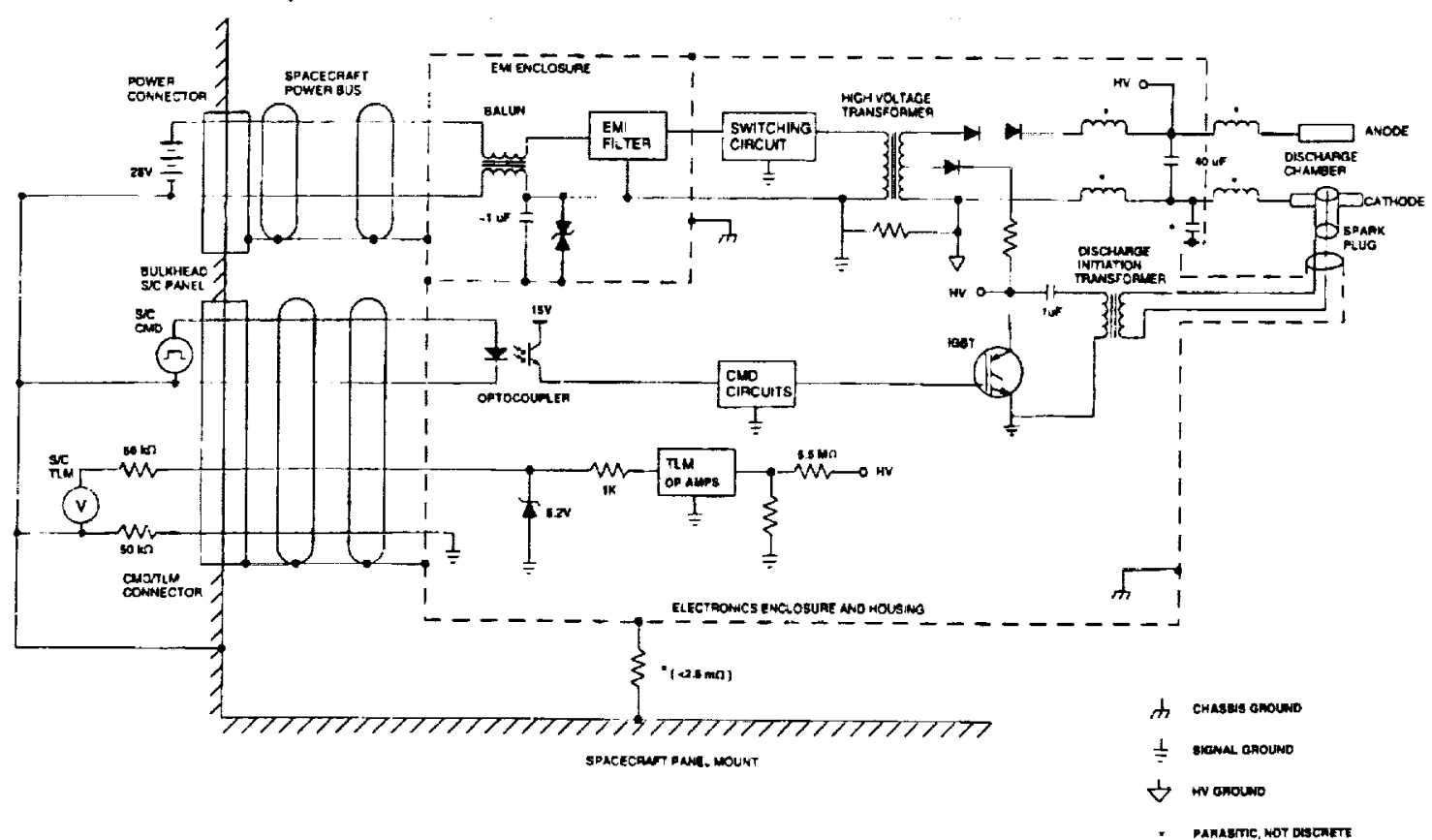

Figure 5.-EO-1 PPT Ground schematic diagram. 


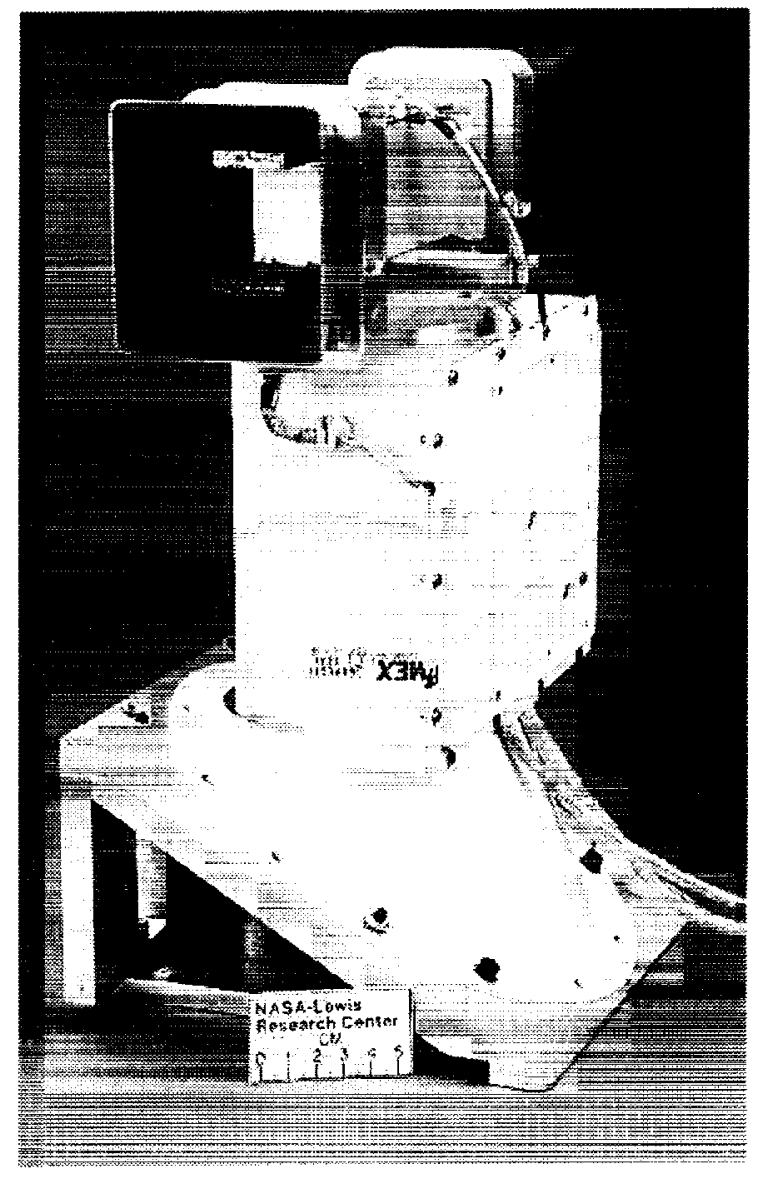

Figure 6.-EO-1 Protoflight pulsed plasma thruster. 


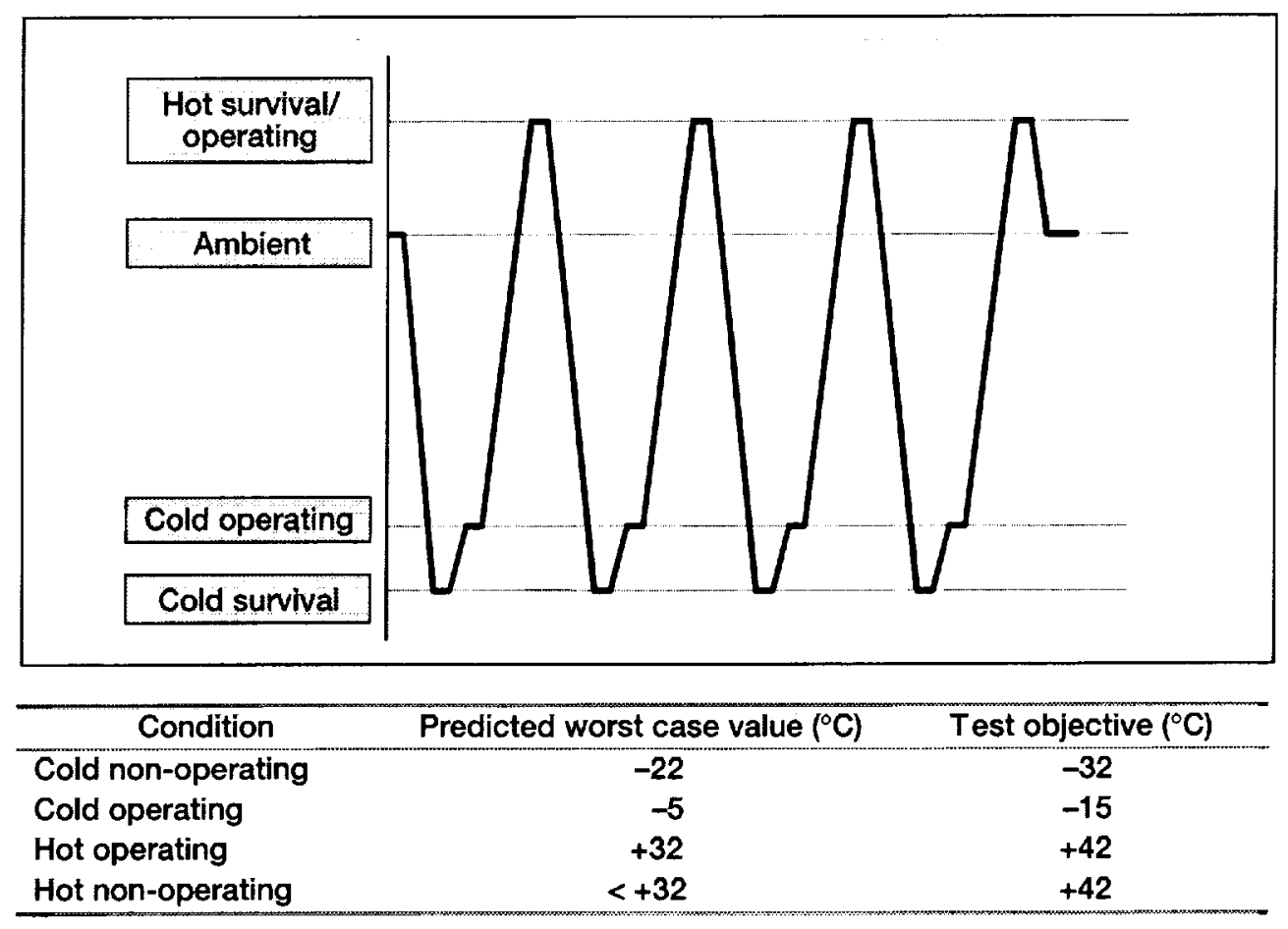

Figure 7.-EO-1 PPT thermal/vacuum test conditions.

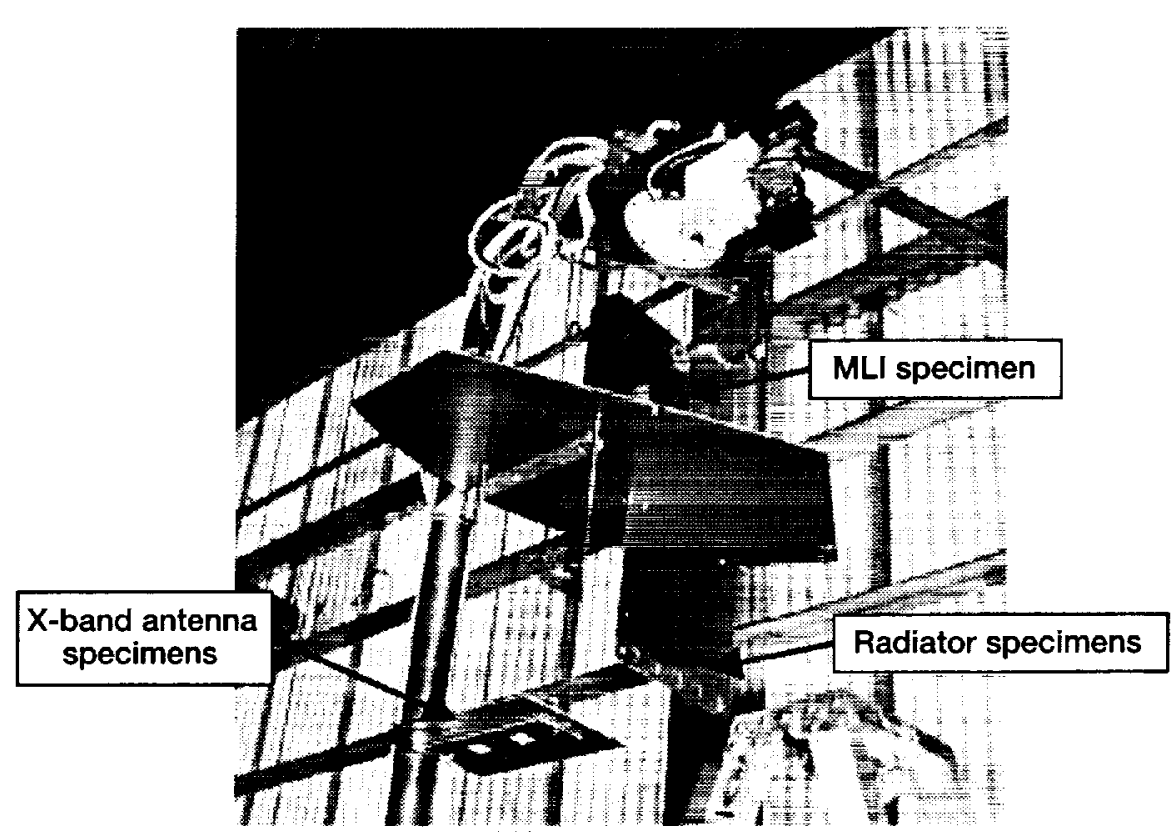

Figure 8.-PPT installed on EO-1 spacecraft mock-up for contamination testing. 

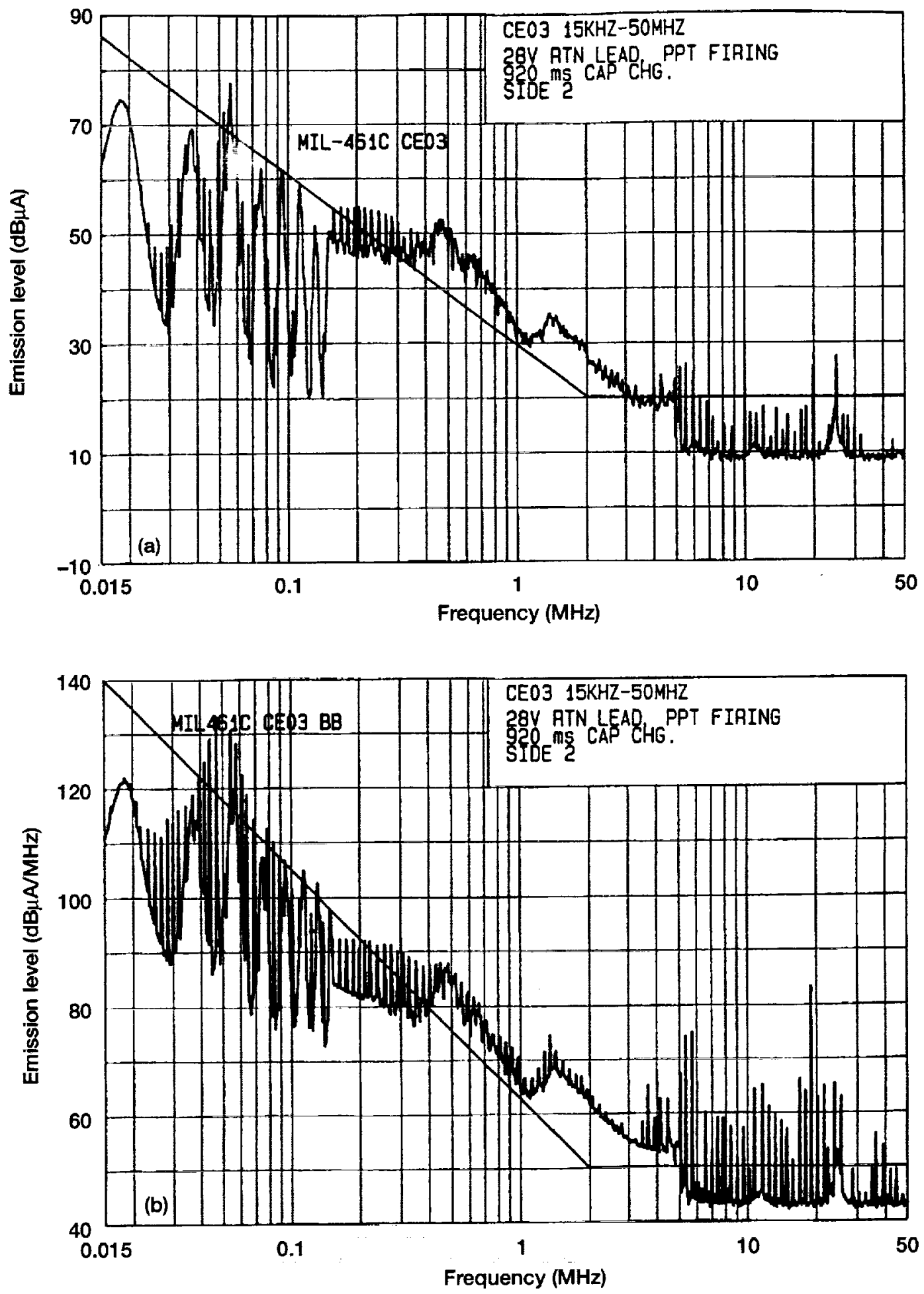

Figure 9.-EO-1 Conducted emissions. Narrowband data applies below $150 \mathrm{kHz}$, broadband data applies above $150 \mathrm{kHz}$. Base of data represents charge cycle, spikes represent pulse events. (a) Narrowband. (b) Broadband. 


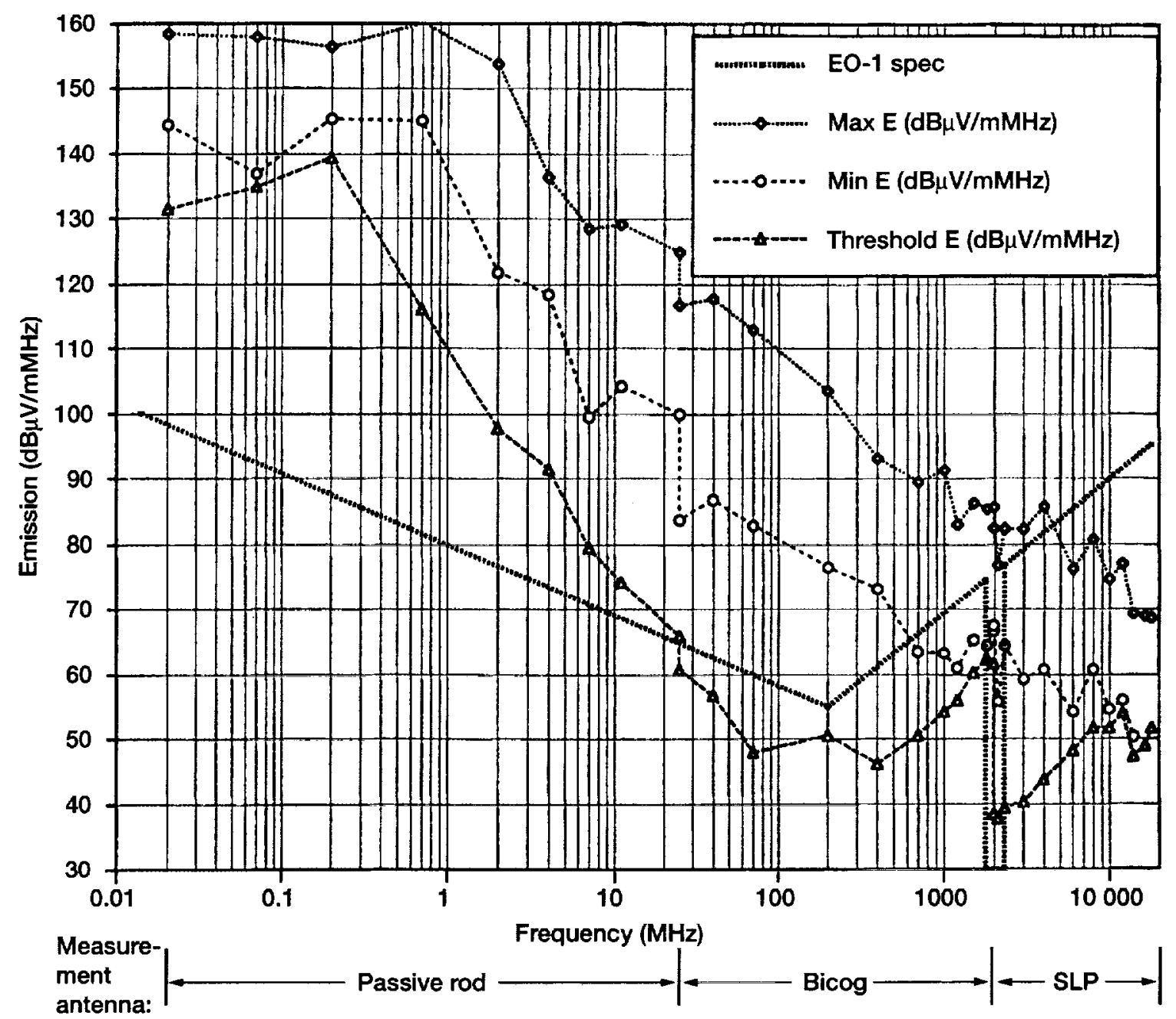

Figure 10.-EO-1 PPT radiated electric field emissions vs. frequency at $1 \mathrm{~m}, 0^{\circ}$ (on thrust axis) position, and vertical polarization. Each point represents the maximum (or minimum) of dominant, $\mu$ s duration spark/discharge emission measured for 100 shots of the PPT. The threshold level for detection at each monitored frequency is shown for reference. 


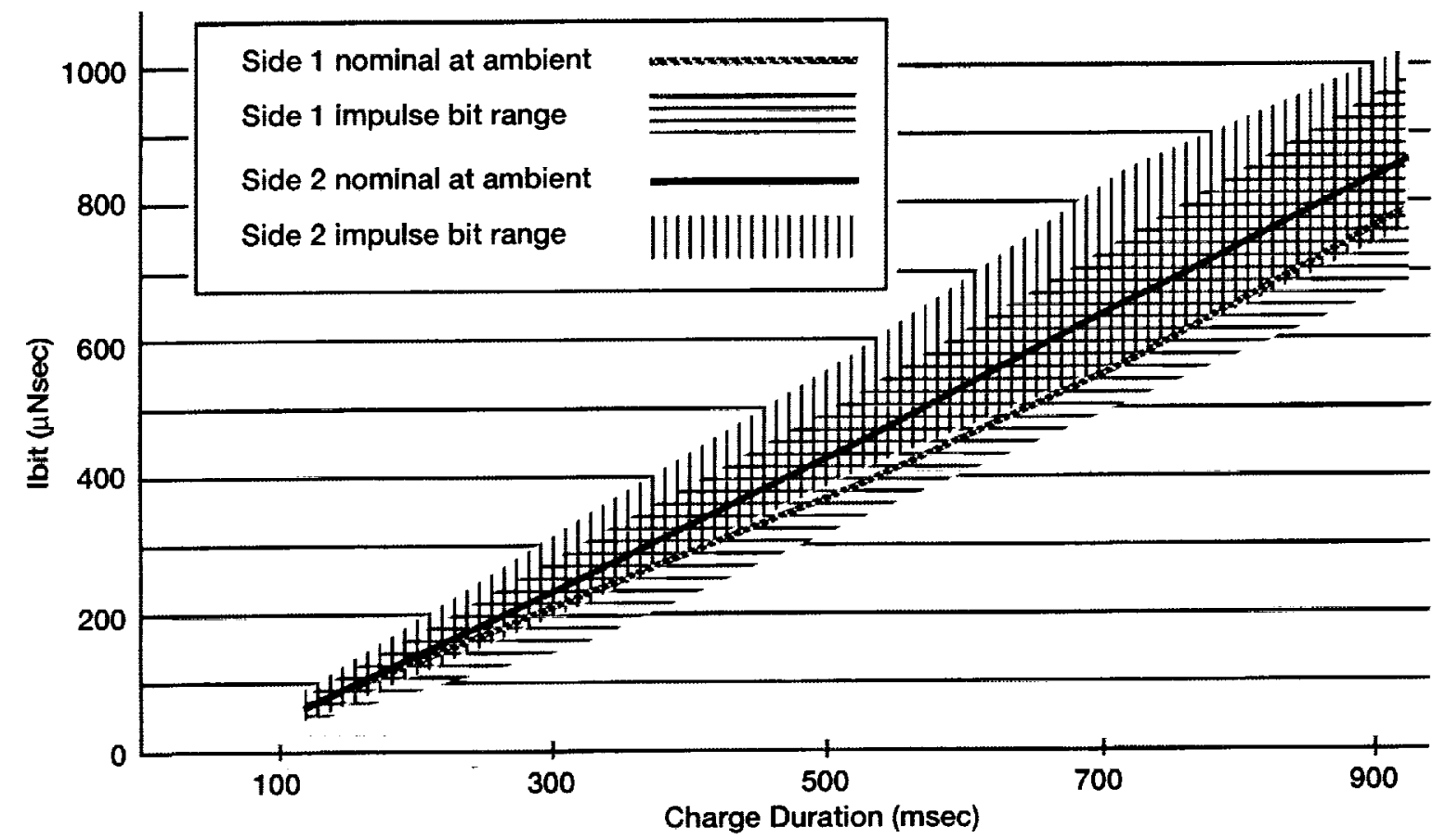

Figure 11.-EO-1 PPT nominal performance, with impulse bit range accounting for shot-to-shot variation and thermal effects within -15 to $+42^{\circ} \mathrm{C}$. 


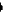
. 
Public reperting burden for this collection of information is estimated to average 1 hour per response, including the time for revlewing instructions, searching existing data sources, gathering and maintaining the data needed, and completing and reviewing the collection of information. Send comments regarding this burden estimate or any other aspect of this Davis Highway, Sulte 1204, Artington, VA 22202-4302, and to the Office of Management and Budget, Paperwork Reduction Project (0704-0188), Washington, DC 20503.

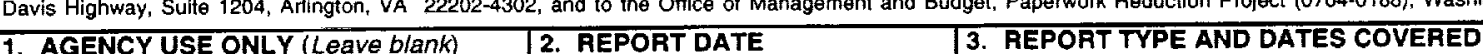

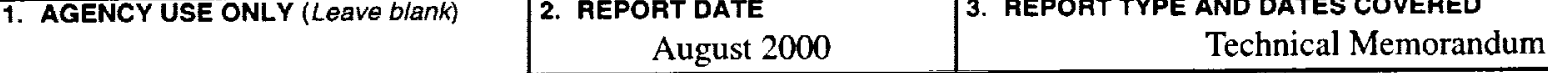

4. TITLE AND SUBTITLE

5. FUNDING NUMBERS

Development of a PPT for the EO-1 Spacecraft

6. AUTHOR(S)

WU-632-6B-1B-00

Scott W. Benson, Lynn A. Arrington, W. Andrew Hoskins, and Nicole J. Meckel

7. PERFó̄MING ORGANIZATION NAME(S) AND ADDRESS(ES)

National Aeronautics and Space Administration

John H. Glenn Research Center at Lewis Field

Cleveland, Ohio 44135-3191

8. PERFORMING ORGANIZATION

REPORT NUMBER

E-12386

\section{SPONSORINGMONITORING AGENCY NAME(S) AND ADDRESS(ES)}

National Aeronautics and Space Administration

Washington, DC 20546-0001

10. SPONSORING/MONITORING AGENCY REPORT NUMBER

NASA TM-2000-210340

AIAA-99-2276

\section{SUPPLEMENTARY NOTES}

Prepared for the 35th Joint Propulsion Conference and Exhibit cosponsored by AIAA, ASME, SAE, and ASEE, Los Angeles, California, June 20-24, 1999. Scott W. Benson, NASA Glenn Research Center; Lynn A. Arrington, Dynacs Engineering Company, Inc., 2001 Aerospace Parkway, Brook Park, Ohio 44142; W. Andrew Hoskins and Nicole J. Meckel, Primex Aerospace Company, P.O. Box 47009, Redmond, Washington 98023. Responsible person, Scott Benson, organization code 6910, (216) 977-7085.

12a. DISTRIBUTION/AVAILABILITY STATEMENT

12b. DISTRIBUTION CODE

Unclassified-Unlimited

Subject Category: 20

Distribution: Nonstandard

This publication is available from the NASA Center for AeroSpace Information, (301) 621-0390.

13. ABSTRACT (Maximum 200 words)

A Pulsed Plasma Thruster (PPT) has been developed for use in a technology demonstration flight experiment on the Earth Observing 1 (EO-1) New Millennium Program mission. The thruster replaces the spacecraft pitch axis momentum wheel for control and momentum management during an experiment of a minimum three-day duration. The EO-1 PPT configuration is a combination of new technology and design heritage from similar systems flown in the 1970's and 1980's. Acceptance testing of the protoflight unit has validated readiness for flight, and integration with the spacecraft, including initial combined testing, has been completed. The thruster provides a range of capability from $90 \mu \mathrm{N}$-sec impulse bit at $650 \mathrm{sec}$ specific impulse for $12 \mathrm{~W}$ input power, through $860 \mu \mathrm{N}$-sec impulse bit at $1400 \mathrm{sec}$ specific impulse for $70 \mathrm{~W}$ input power. Development of this thruster reinitiates technology research and development and re-establishes an industry base for production of flight hardware. This paper reviews the EO-1 PPT development, including technology selection, design and fabrication, acceptance testing, and initial spacecraft integration and test.

\section{SUBJECT TERMS}

Electric propulsion; Pulsed plasma thruster

15. NUMBER OF PAGES 24

16. PRICE CODE

A03

17. SECURITY CLASSIFICATION
OF REPORT
Unclassified

18. SECURITY CLASSIFICATION
OF THIS PAGE
Unclassified

19. SECURITY CLASSIFICATION OF ABSTRACT Unclassified 